\title{
Sistem Pendukung Keputusan Untuk Menentukan Pelanggan Terbaik Pada Pizza Oei-Oei Medan Menggunakan Metode SAW
}

\author{
Muhammad Yusuf ${ }^{*}$, Hasanul Fahmi \\ ${ }^{1,2}$ STMIK Pelita Nusantara \\ Jl. Iskandar Muda No. 1 Medan 20154 \\ Corresponding author's e-mail: ragilyusuf308@gmail.com
}

\begin{abstract}
Abstrak - Manajemen Pizza Oei-Oei Medan belum memiliki standar sistem dalam menentukan pelanggan terbaik.m Selama ini dilakukan secara acak dan tanpa terstruktur dalam menentukan pelanggan terbaik. Tidak Fair bagi pelanggan yang lain. Dibutuhkan suatu sistem pendukung keputusan untuk menentukan pelanggan terbaik yang dapat menghasilkan keputusan dari berbagai alternatif dan kriteria yang ada dalam menentukan pelanggan terbaik dengan fair. Adapun metode yang digunakan adalah SAW (Simple Additive Weighting). SAW merupakan metode yang dapat menentukan nilai bobot untuk setiap atribut, kemudian dilanjutkan dengan proses perankingan yang akan menyeleksi alternatif terbaik dari sejumlah alternatif. Metode SAW dapat diimplementasikan untuk mengetahui pelanggan terbaik berdasarkan kriteria dan bobot yang ditentukan secara benar. Penelitian ini untuk menentukan pelanggan terbaik pada Pizza Oei-oei Medan. Sistem dibangun dengan bahasa pemrograman Visual Basic Studio dengan database Microsoft Access.
\end{abstract}

Kata kunci: Kepuasan Pelanggan, Perangkingan, SPK, SAW

Abstract - The management of Pizza Oei-Oei Medan does not yet have a standard system in determining the best customer.m So far, this has been done randomly and without a structure in determining the best customer. Not fair to other customers. It takes a decision support system to determine the best customers who can make decisions from various alternatives and existing criteria in determining the best customers fairly. The method used is SAW (Simple Additive Weighting). SAW is a method that can determine the weight value for each attribute, then proceed with a ranking process that will select the best alternative from a number of alternatives. SAW method can be implemented to find out the best customers based on the criteria and weights that are determined correctly. This research is to determine the best customers at Pizza Oei-Oei Medan. The system is built with Visual Basic Studio programming language with Microsoft Access database.

Keywords: Customer Satisfaction, Ranking, DSS, SAW

\section{Pendahuluan}

Pelanggan merupakan instansi, lembaga, organisasi ataupun orang yang membeli produk atau jasa perusahaan secara rutin atau berkesinambungan karena produk atau jasa yang dibelinya merasa sangat bermanfaat. Pada suatu usaha ditengah persaingan bisnis yang semakin ketat, baik bersakala besar, sedang bahkan kecil sekalipun, diperlukannya seorang pelanggan. Pelanggan berperan dalam menentukan bergeraknya kehidupan suatu bisnis. Berhasil atau tidaknya suatu perusahaan dalam menjalankan kegiatan bisnisnya dapat dilihat dari perkembangan volume penjualan atas produk yang dijualnya. Disisi lain banyaknya perusahaan pesaing memaksa perusahaan untuk memikirkan bagaimana cara agar perusahaan memperoleh keuntungan yang meningkat dengan cara menambah pelanggan baru dan mempertahankan pelanggan lama. Untuk menarik pihak pelanggan dilakukanlah inovasi-inovasi dan pelayanan yang semakin baik terutama untuk bisnis dibidang makanan. Pizza Oei-oei Medan merupakan salah satu bisnis yang bergerak dibidang makanan. Bisnis tersebut menyediakan makanan seperti Pizza dengan varian rasa, cokelat, soft drink, Donat, Roti Garlic dan makanan ringan lainnya. Pemesanan dapat dilakukan dengan datang langsung ke toko ataupun via online. Saat ini belum adanya sistem untuk memberikan keputusan dalam menentukan pelanggan terbaik. Selama ini hanya dilakukan secara acak tanpa terstruktur dan menjadi tidak fair [1].

Beberapa penelitian sebelumnya tentang penentuan pelanggan terbaik, diantaranya adalah "Penentuan Peringkat Pelanggan Terbaik dengan Metode Weighted Product (Studi Kasus PT. ASIA RAYA Foundry), tujuan dari penelitian ini adalah menentukan peringkat pelanggan terbaik dimana pelanggan terbaik nantinya akan diberi bonus, harga khusus atau promo-promo menarik dan prioritas pengerjaan agar pelanggan tersebut tetap menjadi pelanggan setia disamping itu juga harus memperhatikan pelanggan lainnya. Data pelanggan yang diolah dalam penelitian ini adalah data historis pemesanan pelanggan di bagian marketing, dan dengan didukung metode Weighted Product [2]. Hasil dari penelitan ini adalah sistem pendukung keputusan untuk membuat peringkat dan penentuan pelanggan terbaik agar pihak marketing mampu menganalisa pelanggan dengan cepat dan tepat, penelitian ini adalah telah mampu membuat aplikasi sistem pendukung keputusan dan 
menerapkan metode Weighted Product sebagai pemecahan masalah penentuan peringkat pelanggan terbaik di PT. Asia Raya Foundry dan mendapatkan hasil yang sama antara perhitungan manual dan perhitungan di sistem. Penelitian Sistem Pendukung Keputusan Menentukan Pelanggan Terbaik Ditoko Bangunan Menggunakan Metode WASPAS, Pemilihan pelanggan terbaik ini dilakukan untuk membantu meningkatkan daya tarik pelanggan agar menjadi lebih menarik dalam berbelanja di toko. Untuk membantu menetuan atau pun pemilihan seorang pelanggan terbaik maka dibutuhkan sebuah sistem pendukung keputusan [3]. Pada setiap penelitian akan diangkat sebuah kasus yaitu penetuan pelanggan terbaik pada toko bangunan berdasarkan kriteria-kriteria yang telah ditentukan dengan menggunakan motode Weight Aggregated Sum Product Assesment (WASPAS) [4]. Penelitian dilakukan dengan mencari nilai bobot untuk setiap atribut, kemudian dilakukan proses perangkingan yang akan menetukan alternatif yang optimal, yaitu pelanggan terbaik [5].

\section{Tinjauan Pustaka}

2.1. Sistem Pendukung Keputusan

DSS merupakan sistem informasi interaktif yang menyediakan informasi, pemodelan, dan pemanipulasi data. Sistem digunakan untuk membantu pengambilan keputusan dalam situasi yang semiterstruktur dan situasi tidak terstruktur, dimana tak seorang pun tahu secara pasti bagaimana keputusan seharusnya dibuat [6]. DSS biasanya dibangun untuk mendukung solusi atau suatu masalah atau untuk mengevaluasi suatu peluang. DSS tidak dimaksukan untuk mengotomatisasikan pengambilan keputusan, tetapi memberikan perangkat interaktif yang memungkinkan pengambilan keputusan untuk melakukan berbagai analisis menggunakan model-model yang tersedia [7]. Keputusan semiterstruktur adalah keputusan yang mempunyai sifat yakni sebagian keputusan dapat ditangani oleh komputer dan yang lain tetap harus dilakukan oleh pengambil keputusan[8]. Informasi yang dibutuhkan folus, spesifik, interaktif, internal, real time, dan terjadwal. Keputusan tak terstruktur adalah keputusan yang penanganannya rumit karena tidak terjadi berulang-ulang atau tidak selalu terjadi. Keputusan ini menuntut pengalaman dan berbagai sumber yang bersifat eksternal. Keputusan ini umumnya terjadi pada manajemen tingkat atas. Informasi yang dibutuhkan umum, luas, internal, dan eksternal [9].

\subsection{Metode Simple Additive Weighting (SAW)}

Konsep dasar metode Simple Additive Weighting adalah mencari penjumlahan terbobot dari rating kinerja pada setiap alternatif pada semua atribut [10]. Metode ini membutuhkan proses normalisasi matriks keputusan kedalam skala yang dapat diperbandingkan dengan semua rating alternatif yang ada [11]. Skor total untuk alternative diperoleh dengan menjumlahkan seluruh hasil perkalian antara rating dan bobot tiap atribut Ada beberapa metode yang dapat digunakan untuk menyelesaikan masalah FMADM antara lain:

1. Simple Additive Weighting Method (SAW)

2. Weighted Product (WP)

3. ELECTRE

4. Technique for Order Preference by Similarity to Ideal Solution (TOPSIS)

5. Analytic Hierarchy Process (AHP)

Konsep dasar metode Simple Additive Weighting adalah mencari penjumlahan terbobot dari rating kinerja pada setiap alternatif pada semua atribut [12]. Metode ini membutuhkan proses normalisasi matriks keputusan kedalam skala yang dapat diperbandingkan dengan semua rating alternatif yang ada. Skor total untuk alternative diperoleh dengan menjumlahkan seluruh hasil perkalian antara rating dan bobot tiap atribut [13].

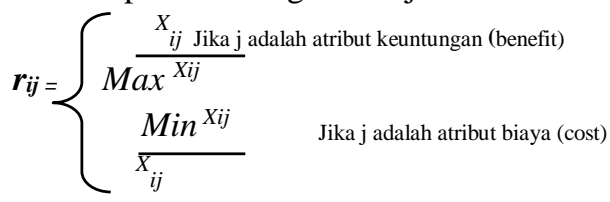

\section{Metode Penelitian}

Tahapan penelitian dilakukan beradasarkan Model Waterfall :

1. Identifikasi Masalah

Identifikasi masalah adalah proses terpenting dari sebuah penelitian selain latar belakang dan perumusan masalah, begitu pentingnya bahkan suatu kegiatan tidak di katakan sebagai sebuah penelitian jika identifikasi masalah yang dibuat asal-asalan. Identifikasi masalah pada penelitian ini adalah tentang penentuan pelanggan terbaik di Pizza Oei-oei Medan. Penentuan ini membutuhkan sebuah sistem pendukung keputusan agar tidak terjadinya pemilihan sepihak dari manajamen tanpa adanya seleksi. Pada tahap ini dilengkapi dengan data 
penelitian seperti, data pelanggan, variable, kriteria dan bobot nilai.

2. Analisis Kebutuhan Sistem

Analisa kebutuhan sistem adalah memahami dengan sesungguhnya kebutuhan dari sistem yang dibutuhkan.

Pada analisis kebutuhan system ini dilakukan dengan 2 tahap yaitu sebagai berikut :

a. Kebutuhan fungsional.

b. Kebutuhan non fungsional, Perangkat keras (Hardware), Perangkat lunak (Software).

3. Analisis Metode

Analisis metode adalah metode yang diterapkan dalam proses penelitian dan ditentukan dengan metode penelitian yang digunakan. Dalam penelitian ini menggunakan sistem pendukung keputusan dengan metode SAW yaitu menghitung alternative dan kriteria berdasarkan cost dan benefit serta bobot yang diberikan.

4. Perancangan Sistem

Perancangan sistem adalah merancang atau mendesain suatu sistem yang baik, yang isinya adalah langkahlangkah operasi dalam proses pengolahan data dan prosedur untuk mendukung operasi sistem. Perancangan sistem ini terdiri dari perancangan aplikasi UML, perancangan database menggunakan Access, dan desain user interface.

5. Implementasi Sistem

Implementasi adalah suatu penerapan atau tindakan yang dilakukan berdasarkan rencana yang telah disusun dan dibuat dengan cermat dan terperinci, sedangkan pengujian adalah proses yang bertujuan untuk memastikan apakah semua fungsi sistem berjalan dengan baik dan mencari kesalahan yang mungkin terjadi pada sistem. Pada tahap implementasi ini sistem pendukung keputusan penentuan pelanggan terbaik di Pizza Oei-oei Medan dibangun dengan bahasa pemrograman Visual Basic dan tahap pengujian sistem dilakukan dengan blackbox testing yang bertujuan untuk memastikan bahwa aplikasi sudah sesuai dengan kebutuhan.

\section{Hasil dan Pembahasan}

Pengumpulan data berupa data nama-nama pelanggan yang sering beli atau pesan berdasarkan karakteristiknya masing-masing. Pengumpulan data dilakukan dengan menganalisa data. Adapun dalam penilaian setiap atribut menggunakan Pendekatan Nilai Aktual dengan range nilai 0 s/d 1 dengan normalisasi.Penelitian ini bertujuan untuk mengetahui bagaimana membuat sistem untuk menentukan pelanggan terbaik berdasarkan data alternatif dan kriteria yang telah didapatkan melalui diskusi. Analisa sistem merupakan langkah-langkah perancangan sistem yang direpresentasikan pada tahapan yang dilakukan pada studi kasus penelitian menggunakan metode Simple Additive Weighting dengan tahapan sebagai berikut:

1. Menentukan alternatif,yaituAi.

1. Menentukan kriteria yang akan dijadikan acuan dalam pengambilan keputusan, yaitu $\mathrm{Cj}$.

2. Memberikan nilai rating kecocokan setiap alternatif pada setiap kriteria.

3. Menentukan bobot preferensi atau tingkat kepentingan (W) setiap kriteria.

4. Membuat tabel rating kecocokan dari setiap alternatif pada setiap kriteria.

5. Membuat matrik keputusan yang dibentuk dari table rating kecocokan darisetiap alternative pada setiap kriteria

6. Melakukan normalisasi matrik keputusan dengan cara menghitung nilai rating kinerja ternomalisasi (rij) dari alternative Ai pada kriteria $\mathrm{Cj}$.

7. Hasil dari nilai rating kinerja ternomalisasi (rij) membentuk matrik ternormalisasi (R)

8. Hasil akhir nilai preferensi (Vi ).

Metode Simple Additive Weighting dapat di artikan sebagai metode pembobotan sederhana atau penjumlahan terbobot pada penyelesaian masalah dalam sebuah sistem pendukung keputusan. Konsep metode ini adalah dengan mencari rating kinerja (skala prioritas) pada setiap alternatif di semua atribut. 
Tabel 1.Data Kriteria

\begin{tabular}{|c|c|c|c|}
\hline No & Kode & Nama Kriteria & $\begin{array}{c}\text { Jenis } \\
\text { Kriteria }\end{array}$ \\
\hline 1. & C01 & Total Belanja & Benefit \\
\hline 2. & C02 & $\begin{array}{c}\text { Keaktifan Belanja } \\
\text { (Perbulan) }\end{array}$ & Benefit \\
\hline 3. & C03 & ekuensi Komplain & Cost \\
\hline 4. & C04 & Jarak Tempuh & Benefit \\
\hline
\end{tabular}

Tabel 4 Data Kriteria

\begin{tabular}{|c|c|c|}
\hline No. & Kriteria & Nilai \\
\hline 1. & Ada Komplain & 1 \\
\hline 2. & Tidak Ada Komplain & 0.25 \\
\hline
\end{tabular}

Tabel 2. Kriteria Penilaian Total Belanja (C01)

\begin{tabular}{|c|c|c|}
\hline $\begin{array}{c}\text { No } \\
.\end{array}$ & Kriteria & $\begin{array}{c}\text { Nil } \\
\text { ai }\end{array}$ \\
\hline 1. & $>=$ Rp. 151.000 & 1 \\
\hline 2. & Rp.101.000- & 0.7 \\
Rp. 150.000 & 5 \\
\hline 3. & Rp. $51.000-$ & 0.5 \\
& Rp. 100.000 & 0 \\
\hline 4. & Rp. $10.000-$ & 0.2 \\
Rp. 50.000 & 5 \\
\hline
\end{tabular}

Tabel 3. Kriteria Penilaian Keaktifan Belanja (Perbulan)

\begin{tabular}{|c|c|c|}
\hline $\begin{array}{c}\text { No } \\
.\end{array}$ & Kriteria & $\begin{array}{c}\text { Nil } \\
\text { ai }\end{array}$ \\
\hline 1. & $\begin{array}{c}>=7 \\
\text { kali }\end{array}$ & 1 \\
\hline 2. & $\begin{array}{c}5-6 \\
\text { kali }\end{array}$ & $\begin{array}{c}0.7 \\
5\end{array}$ \\
\hline 3. & $\begin{array}{c}3-4 \\
\text { kali }\end{array}$ & $\begin{array}{c}0.5 \\
0\end{array}$ \\
\hline 4. & $\begin{array}{c}1-2 \\
\text { kali }\end{array}$ & $\begin{array}{c}0.2 \\
5\end{array}$ \\
\hline
\end{tabular}

Tabel 5. Kriteria Penilaian Jarak Tempuh (C04)

\begin{tabular}{|c|c|c|}
\hline No. & Kriteria & Nilai \\
\hline 1. & $>=451 \mathrm{M}$ & 1 \\
\hline 2. & $301 \mathrm{M}-450 \mathrm{M}$ & 0.75 \\
\hline 3. & $151 \mathrm{M}-300 \mathrm{M}$ & 0.50 \\
\hline 4. & $10 \mathrm{M}-150 \mathrm{M}$ & 0.25 \\
\hline
\end{tabular}

Terdapat 5 Kriteria pada penelitian ini masing-masing kriteria memiliki bobot preferensi berdasarkan nilai kepentingan setiap kriteria. Untuk penilaian diambil dari beberapa data alternatif yang diubah kedalam bilangan sebagai studi kasus dalam perhitungan SAW yang kemudian masing-masing jenis kriteria dievaluasi dan diberikan nilai,

Tabel 6. Bobot Kriteria

\begin{tabular}{|c|c|c|c|}
\hline Kode & Nama Kriteria & $\begin{array}{c}\text { Jenis } \\
\text { Kriteria }\end{array}$ & Bobot \\
\hline C01 & Total Belanja & Benefit & 0.30 \\
\hline C02 & $\begin{array}{c}\text { aktifan Belanja } \\
\text { (Perbulan) }\end{array}$ & Benefit & 0.30 \\
\hline C03 & $\begin{array}{c}\text { Frekuensi } \\
\text { Komplain }\end{array}$ & Cost & 0.30 \\
\hline C04 & arak Tempuh & Benefit & 0.10 \\
\hline 1 & 100 & \multicolumn{2}{|c}{} \\
\cline { 1 - 2 } & \multicolumn{3}{|c}{}
\end{tabular}

Tabel 7. Penilaian Setiap Alternatif

\begin{tabular}{|l|c|c|c|l|}
\hline $\begin{array}{c}\text { Nama } \\
\text { Pelanggan }\end{array}$ & $\begin{array}{l}\text { Total } \\
\text { Belanja }\end{array}$ & $\begin{array}{c}\text { Keaktifan } \\
\text { Belanja } \\
\text { (Perbulan) }\end{array}$ & $\begin{array}{c}\text { Frekuensi } \\
\text { Komplain }\end{array}$ & $\begin{array}{l}\text { Jarak } \\
\text { empuh }\end{array}$ \\
\hline Fitriana & $\begin{array}{l}\text { Rp. } \\
60.000\end{array}$ & 4 Kali & $\begin{array}{c}\text { Ada } \\
\text { Komplain }\end{array}$ & $\beta 00 \mathrm{M}$ \\
\hline $\begin{array}{l}\text { Dinda ayu } \\
\text { lestari }\end{array}$ & $\begin{array}{c}\text { Rp. } \\
100.000\end{array}$ & 3 Kali & $\begin{array}{c}\text { Ada } \\
\text { Komplain }\end{array}$ & 00 M \\
\hline Asrul & $\begin{array}{c}\text { Rp. } \\
40.000\end{array}$ & 7 Kali & Tidak Ada & $50 \mathrm{M}$ \\
\hline $\begin{array}{l}\text { Hafiza } \\
\text { haqqi }\end{array}$ & $\begin{array}{c}\text { Rp. } \\
250.000\end{array}$ & 10 Kali & $\begin{array}{c}\text { Ada } \\
\text { Komplain }\end{array}$ & $230 \mathrm{M}$ \\
\hline Ocha & $\begin{array}{c}\text { Rp. } \\
170.000\end{array}$ & 5 Kali & Tidak Ada & $189 \mathrm{M}$ \\
\hline
\end{tabular}

Tahap akhir yaitu proses perankingan yaitu penjumlahan dari perkalian matriks ternormalisasi $\mathrm{R}$ dengan vektor bobot sehingga diperoleh nilai terbesar yang dipilih sebagai alternatif terbaik (Ai) dengan persamaan $\mathrm{Vi}=$ $\Sigma w j$. rij

Adapun nilai bobot preferensi (W) pada kriteria C1, C2, C3, C4 yaitu \{0,30:0.30:0.30:0.10\}. Maka nilai Vi untuk tiap alernatif sebagai berikut:

$\mathrm{V} 1=(0.30 * 0.50)+(0.30 * 0.50)+(0.30 * 0.25)+(0.10 * 0.50)$

$=0.15+0.15+0.075+0.05=0.425$

$\mathrm{V} 2=(0.30 * 0.50)+(0.30 * 0.50)+(0.30 * 0.25)+(0.10 * 1)$

$=0.15+0.15+0.075+0.1=0.475$

$\mathrm{V} 3=(0.30 * 0.25)+(0.30 * 1)+(0.30 * 1)+(0.10 * 0.25)$

$=0.075+0.30+0.30+0.025=0.70$

$\mathrm{V} 4=(0.30 * 1)+(0.30 * 1)+(0.30 * 0.25)+(0.10 * 0.50)$

$=0.30+0.30+0.075+0.05=0.725$ 
V5 $=(0.30 * 1)+(0.30 * 0.75)+(0.30 * 1)+(0.10 * 0.50)$

$=0.30+0.225+0.30+0.05=0.875$

Berdasarkan hasil perhitungan dengan metode Simple Additive Weighting pada untuk menentukan pelanggan terbaik, maka yang diprioritaskan untuk mendapatkan bagian terbesar adalan calon penerima yang mendapatkan nilai lebih besar dari 0.85 sehingga diketahui rekapitulasi prioritas.

Implementasi, pada bagian ini membahas tahapan untuk menjalankan sistem dalam bentuk hasil capture sistem yang sedang dijalankan dan setiap gambar dilengkapi dengan penjelasan. Sebelum masuk ke aplikasi, maka diharapkan masuk ke dalam menu login. Menu Login terdiri dari Username dan Password. User diharapkan mengisi username dan Password untuk masuk ke menu utama apikasi. Login tidak dapat dijalankan jika salah satu username dan password tidak diisi. Jika username atau password salah, maka akan muncul notifikasi. Jika yang user isi hanya salah satu, maka akan muncul notifikasi juga. Username dan Password terdiri dari angka. Setelah mengisi, maka klik menu Login untuk masuk ke dalam menu utama atau Menu Home aplikasi. User dapat juga mengklik cancel untuk keluar dari menu login.

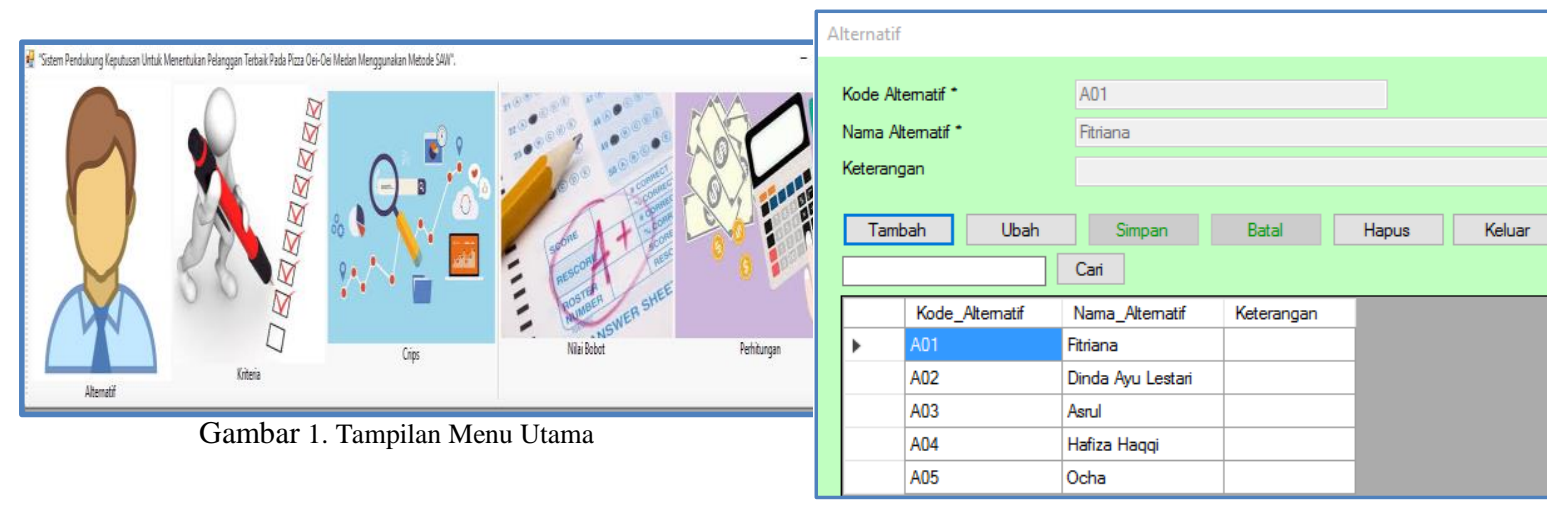

Gambar 2. Tampilan Menu Alternatif

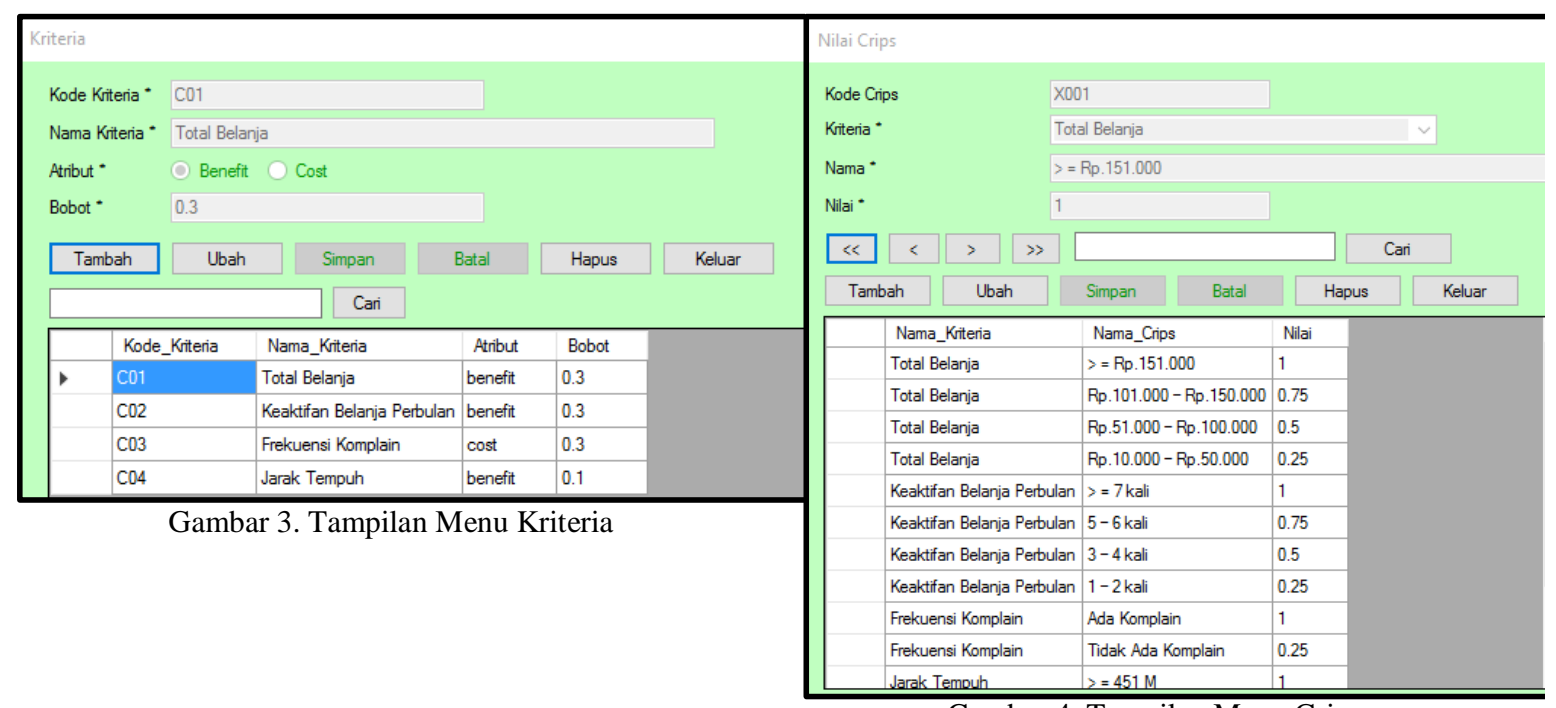

Gambar 4. Tampilan Menu Crips 


\begin{tabular}{|c|c|c|c|c|c|c|c|c|c|c|c|c|c|c|c|c|}
\hline \multirow{3}{*}{ Awal } & \multirow[b]{2}{*}{ Hasil Analisa } & \multirow[b]{2}{*}{ Normalisasi } & \multirow[b]{2}{*}{ Total } & \multirow[b]{2}{*}{ ngking } & & & & \multirow[t]{3}{*}{ Awal } & \multirow[t]{2}{*}{ Hasil Analisa } & \multirow[t]{2}{*}{ Nomalisasi Total } & \multirow{2}{*}{\multicolumn{2}{|c|}{ Rangking }} & \multirow[b]{3}{*}{$\mathrm{CO} 3$} & \multirow{3}{*}{$\mathrm{CO}$} & \multirow{3}{*}{ Total $\checkmark$} & \multirow{3}{*}{ - Keterangan } \\
\hline & & & & & & & & & & & & & & & & \\
\hline & Kode & Nama & $\mathrm{CO1}$ & $\mathrm{CO} 2$ & $\mathrm{CO} 3$ & $\mathrm{CO} 4$ & & & Kode & Nama & C01 & $\mathrm{CO2}$ & & & & \\
\hline \multirow[t]{5}{*}{ - } & A01 & Fitriana & 0.15 & 0.15 & 0.075 & 0.05 & 0 & b & A05 & Ocha & 0.3 & 0.225 & 0.3 & 0.05 & 0.875 & Kategori Pelanggan 7 \\
\hline & A02 & Dinda Ayu Lestar & 0.15 & 0.15 & 0.075 & 0.1 & 0 & & A04 & Hafiza Haqqi & 0.3 & 0.3 & 0.075 & 0.05 & 0.725 & Kategon Pelanggan 1 \\
\hline & A03 & Asrul & 0.075 & 0.3 & 0.3 & 0.025 & 0 & & $A 03$ & Asnul & 0.075 & 0.3 & 0.3 & 0.025 & 0.7 & Kategori Pelanggan 7 \\
\hline & A04 & Hafiza Haqqi & 0.3 & 0.3 & 0.075 & 0.05 & 0 & & A02 & Dinda Ayu Lestan & 0.15 & 0.15 & 0.075 & 0.1 & 0.475 & Belum Kategor Pelan \\
\hline & A05 & Ocha & 0.3 & 0.225 & 0.3 & 0.05 & 0 & & A01 & Fitriana & 0.15 & 0.15 & 0.075 & 0.05 & 0.425 & Belum Kategori Pelan \\
\hline
\end{tabular}

\section{Kesimpulan}

Kesimpulan dari penelitian :

1. Penerapan Metode SAW tepat digunakan untuk menentukan peringkat atau keputusan tdalam menentukan pelanggan terbaik pada pizza Oei-oei Medan.

2. Perancangan aplikasi sistem pendukung keputusan untuk menentukan pelanggan terbaik pada pizza oeioei Medan dapat menggunakan Visual Basic Studio.

\section{Daftar Pustaka}

[1] R. Oktaviana and H. Himawan, "Sistem Pendukung Keputusan Untuk Menentukan Pelanggan Terbaik Pada TB. Bangun Jaya Menggunakan Metode Weighted Product (WP)," Univ. Dian Nuswantoro, pp. 1-9, 2015.

[2] F. Sholikhah, D. H. Satyareni, and C. S. Anugerah, "Perancangan Sistem Pendukung Keputusan Pemilihan Pelanggan Terbaik Menggunakan Metode Simple Additive Weighting (SAW) Pada Bravo Supermarket Jombang," Regist. J. Ilm. Teknol. Sist. Inf., vol. 2, no. 1, p. 40, 2016.

[3] I. S. Putra, F. Ferdinandus, and M. Bayu, "Sistem Pendukung Keputusan Pemilihan Paket Pernikahan Dengan Metode Saw Berbasis Web," CAHAYAtech, vol. 8, no. 2, p. 136, 2019.

[4] G. S. Mahendra and P. G. S. C. Nugraha, "Komparasi Metode AHP-SAW dan AHP-WP pada SPK Penentuan E-Commerce Terbaik di Indonesia," J. Sist. dan Teknol. Inf., vol. 08, no. 4, pp. 346-356, 2020.

[5] Z. Hakim, A. R. Mariana, and N. Safitri, "Sistem Pendukung Keputusan Kepuasan Pelanggan di Minimarket dengan menggunakan Metode SAW," J. Sisfotek Glob., vol. 8, no. 2, 2018.

[6] R. S. Septarini et al., "Rancang Bangun Aplikasi Customer' Ku Untuk Menentukan Kualitas Pelayanan Menggunakan Metode Simple Additive,” pp. 552-559, 2018.

[7] S. S. Putro, "Implementasi Metode Servqual Dan Saw Untuk Analisa Kepuasan Pasien Berdasarkan Kualitas Pelayanan Poli Rawat Jalan,” J. Komunika J. Komunikasi, Media dan Inform., vol. 6, no. 2, pp. 1-9, 2017.

[8] L. Situmorang and J. R. Sagala, "Sistem Pendukung Keputusan Pemilihan Tentor Terbaik Dengan Metode Technique For Order Preference By Similarity To Ideal Solution (Topsis)," J. Nas. Komputasi dan Teknol. Inf., vol. 3, no. 3, pp. 209-214, 2020.

[9] H. Harsiti and H. Aprianti, "Sistem Pendukung Keputusan Pemilihan Smartphone dengan Menerapkan Metode Simple Additive Weighting (SAW)," JSiI (Jurnal Sist. Informasi), vol. 4, pp. 19-24, 2017.

[10] N. Chaniago and A. Sindar, "SPK Penilaian Hasil Belajar Siswa Menggunakan Metode TOPSIS," vol. 9, pp. 41-48, 2020.

[11] J. H. Gurusinga, B. Sinaga, and A. Sindar, "Sistem Pendukung Keputusan Menentukan Prioritas Tujuan Wisata Daerah pada Kabupaten Karo dengan Metode TOPSIS," vol. 5, no. 3, pp. 423-429, 2020.

[12] Refiza, "Penerapan Metode Simple Additive Weighting," Indones. J. Comput. Inf. Technol., vol. 4, no. 2, pp. 96-103, 2019.

[13] Nurul Putri Utami, Hasanul Fahmi, and Anita Sindar, "Spk Penentuan Pemberian Pinjaman Kepada Anggota Bumdes Dengan Metode Simple Additive Weighting," SINTECH (Science Inf. Technol. J., vol. 2, no. 2, pp. 124-130, 2019. 